\title{
Spatial and Temporal Distribution of Mutations Conferring Qol and SDHI Resistance in Alternaria solani Across the United States
}

\author{
Mitchell J. Bauske, Ipsita Mallik, S. K. R. Yellareddygari, and Neil C. Gudmestad, ${ }^{\dagger}$ Department of Plant Pathology, North Dakota State \\ University, Fargo 58105
}

Abstract

\begin{abstract}
The application of succinate dehydrogenase inhibiting (SDHI) and quinone outside inhibiting (QoI) fungicide chemistries is a primary tactic in the management of early blight of potato, caused by Alternaria solani. Resistance to QoIs in A. solani has been attributed to the F129L mutation, while resistance to SDHIs is conferred by five different known point mutations on three $A s S d h$ genes. In total, 1,323 isolates were collected from 2013 through 2015 across 11 states to determine spatial and temporal frequency distribution of these mutations. A real-time polymerase chain reaction (PCR) was used to detect the presence of the F129L mutation. Molecular detection of SDHI-resistant isolates was performed using SDH multiplex PCR specific for point mutations in AsSdhB, AsSdhC, or $A s S d h D$ genes and mismatch amplification analysis PCR detecting the point mutations in $A s S d h B$. Previous work in our research group determined that substitutions of histidine for tyrosine $(\mathrm{H} 278 \mathrm{Y})$ or arginine
\end{abstract}

(H278R) at codon 278 on the $A s S d h B$ gene were the most prevalent mutations, detected in 46 and $21 \%$ of $A$. solani isolates, respectively, collected in 2011 to 2012, and uniformly distributed among six sampled states. In contrast, the substitution of histidine for arginine (H134R) at codon 134 in the As $S d h C$ gene was the most prevalent mutation in 2013 through 2015, identified in $36 \%$ of isolates, compared with $7.5 \%$ of isolates recovered in 2011 to 2012. Substitutions of histidine for arginine (H133R) at codon 133 and aspartic acid for glutamic acid (D123E) at codon 123 in the $A s S d h D$ gene were detected in 16 and $12 \%$, respectively, in the A. solani population by 2015 and were recovered across a wide range of states, compared with 15 and $1.5 \%$ of isolates collected in 2011 to 2012, respectively. Overall, SDHI- and QoI-resistant isolates were detected at high frequencies across all years, with evidence of significant spatial variability. Future research will investigate whether these results are due to differences in parasitic fitness.
Early blight of potato (Solanum tuberosum L.), caused by Alternaria solani Sorauer, is a chronic foliar disease of potato present every growing season throughout many potato production areas and can cause significant yield reductions of up to $30 \%$ (Pscheidt and Stevenson 1988; Franc and Christ 2001). Because most currently grown potato cultivars are susceptible to early blight, the primary method of disease control is the application of foliar fungicides. Although mancozeb and chlorothalonil remain the most frequently applied protectant fungicides for the control of early blight, they provide insufficient control under high disease pressure (Gudmestad et al. 2013; Yellareddygari et al. 2016). The single-site mode-of-action chemistries of the succinate dehydrogenase inhibiting (SDHI) and quinone outside inhibiting (QoI) fungicides have been widely used for early blight control but resistance has developed rapidly to a number of fungicide chemistries (Gudmestad et al. 2013; Miles et al. 2014; Pasche et al. 2004, 2005). The biochemical mode of action is similar in SDHIs and QoIs, because they both inhibit the mitochondrial respiration process, SDHI at complex II and QoI at complex III (Stammler et al. 2007).

The QoI fungicide azoxystrobin was introduced in 1999 and initially provided excellent early blight control (Stevenson and James 1999) but reduced disease control was observed in A. solani by 2001 (Pasche et al. 2004). Although QoI resistance in other pathogens is associated with the G143A mutation, or the substitution of glycine with alanine at position 143 in the cytochrome $\mathrm{b}(\mathrm{cytb})$ gene, reduced sensitivity in $A$. solani is attributed to the F129L mutation, or the substitution of phenylalanine with leucine at position 129 (Pasche et al. 2005). The F129L mutation conveys a moderate level of resistance to QoI fungicides such as azoxystrobin and pyraclostrobin, resulting in a 12- to 15 -fold reduction in sensitivity (Pasche et al. 2004, 2005). In a survey conducted from 2002 through 2006, the prevalence of F129L-mutant $A$. solani isolates was $96.5 \%$, predominating the population of isolates collected across 11 states (Pasche and Gudmestad 2008). Also within the cytb gene, there are two known genotypes of

${ }^{\dagger}$ Corresponding author: N. C. Gudmestad; E-mail: neil.gudmestad@ ndsu.edu Accepted for publication 28 September 2017.

@ 2018 The American Phytopathological Society
A. solani differing by the presence or absence of an intron (Leiminger et al. 2014). A previous study detected both genotypes in A. solani collections from Germany and a small number of isolates from the United States (Leiminger et al. 2014) but little is known about the spatial distribution of each genotype.

In 2005, the SDHI fungicide boscalid was registered for use on potato and provided effective early blight control after the development of resistance in A. solani to azoxystrobin. Unfortunately, A. solani isolates found to be insensitive to boscalid were recovered in Idaho in 2009 (Wharton et al. 2012). Resistance to SDHI fungicides in A. solani is conferred by five known point mutations on three AsSdh genes: two on the AsS $d h B$ gene, one on As $S d h C$ gene, and two on the As $S d h D$ gene (Mallik et al. 2014). Similar to mutations identified in A. alternata, each mutation identified in the three target-encoding genes in A. solani can independently confer resistance to SDHI fungicides (Avenot et al. 2008; Mallik et al. 2014). Point mutations on the $A s S d h B$ gene leading to an exchange from histidine to tyrosine (H278Y) or arginine (H278R) at codon 278 are associated with moderate to high levels of resistance to boscalid and penthiopyrad. A point mutation in the $A s S d h C$ gene leading to an exchange from histidine to arginine (H134R) at codon 134 confers very high boscalid and penthiopyrad resistance. Two additional point mutations on the $A s S d h D$ gene leading to exchanges from histidine to arginine (H133R) at codon 133 and aspartic acid to glutamic acid (D123E) at codon 123 are also associated with high levels of resistance to boscalid and penthiopyrad (Mallik et al. 2014). None of the SDHI mutations identified to date affect the sensitivity of $A$. solani to fluopyram (Mallik et al. 2014; Miles et al. 2014).

In addition to A. solani, mutations conferring SDHI resistance have been identified in many pathogens, including A. alternata, Botrytis cinerea, Corynespora cassiicola, Didymella bryoniae, and Podosphaera xanthii, (Avenot and Michailides 2010; Avenot et al. 2008, 2012; Bardas et al. 2010; Ishii et al. 2011), among others. Several studies have suggested evidence of spatial variability of mutations in SDH subunits conveying resistance. For example, mutations in the $B c S d h B$ gene conferring SDHI resistance in $B$. cinerea were shown to be widely variable among production areas, with five SDH mutations detected in isolates recovered from Greek strawberry fields and seven different mutations detected in isolates recovered from grape in France (Konstantinou et al. 2015; Leroux et al. 2010). In the Greek 
strawberry population of $B$. cinerea, the $\mathrm{H} 272 \mathrm{R}$ mutation was the most prevalent (Konstantinou et al. 2015) but, in the French grape population, the $\mathrm{H} 272 \mathrm{Y}$ was detected at the highest frequency (Leroux et al. 2010). B. cinerea isolates possessing the $\mathrm{H} 272 \mathrm{R}$ and $\mathrm{H} 272 \mathrm{Y}$ mutations were also predominate in blackberry and strawberry fields in South and North Carolina, with the two mutations appearing at a ratio of 2:1, respectively ( $\mathrm{Li}$ et al. 2014).

In SDHI-resistant isolates of $A$. alternata recovered from pistachio in California, mutations were detected in the $A a S d h B, A a S d h C$, and $A a S d h D$ genes but isolates possessing mutations in the $A s S d h D$ gene were detected at lower frequencies (Avenot and Michailides 2010; Avenot et al. 2009). Mutations on all three SDH genes were also identified in isolates of A. alternata collected from peach orchards in South Carolina, with the H134R mutation on the AaSdhC gene found to be the most prevalent (Yang et al. 2015). In a survey of A. solani in 2011 to 2012, isolates possessing mutations in the $A s S d h B$ gene were recovered at the highest frequencies and uniformly distributed among six states, whereas isolates possessing mutations on the $A s S d h C$ and $A s S d h D$ genes were recovered at lower frequencies and appeared to be region specific (Mallik et al. 2014). For example, A. solani isolates possessing the $\mathrm{H} 278 \mathrm{Y}$ mutation were collected in all six sampled states and constituted $46 \%$ of the population, whereas isolates with the H134R mutation constituted $7.5 \%$ of the population and were only recovered in North Dakota and Idaho. Furthermore, the D123E mutation was detected in only a single isolate, which was recovered from Nebraska. Despite variation in spatial distribution of mutations associated with fungicide resistance in the aforementioned pathogens, very little is known about temporal variation throughout multiple years.

A key element of fungicide resistance management is the continued monitoring of resistance development in fungal populations over time, which can allow predictions of pathogen behavior, detect shifts in pathogen sensitivity, assess efficacy of fungicide regimes, and recommend effective resistance management tactics (Thomas et al. 2012). In addition to collecting a spatially and temporally diverse $A$. solani population from potato, the objectives of this study were to (i) determine the overall prevalence of SDHI and QoI resistance in A. solani, (ii) determine temporal frequency of mutations conferring SDHI and QoI resistance from 2011 through 2015, and (iii) determine spatial frequency of mutations conferring SDHI and QoI resistance across potato production areas in the United States.

\section{Materials and Methods}

A. solani isolate collection. In total, 1,323 A. solani isolates collected from 2013 through 2015 were obtained from foliar and tuber samples submitted to the Neil C. Gudmestad Laboratory of Potato Pathology from potato production areas in 11 states across the United States including North Dakota, Minnesota, Nebraska, Texas, Colorado, New Mexico, Idaho, Washington, Michigan, Illinois, and Wisconsin (Table 1). Approximately 15 to 20 infected leaves were randomly collected by a third party (potato grower, crop consultant, or agronomist) across each early blight-symptomatic potato field, stored with a damp paper towel in a plastic bag, and mailed directly to our laboratory. Throughout a number of these states, the same growers submitted early blight-symptomatic tissue samples from a number of fields every year (Table 1). Although the exact fields were not sampled repeatedly every year from 2013 to 2015 due to a 3- to 4-year recommended crop rotation, samples were obtained from a $55-$ to $65-\mathrm{km}$ radius. Three to five infected leaflets from each field were stored in a herbarium press for preservation of the original collection. A. solani isolates were obtained by transferring a small portion of plant tissue from the margin of early blight lesions directly to solid $1.5 \%$ water agar media and grown at room temperature $\left(22 \pm 2^{\circ} \mathrm{C}\right)$ for 4 days until conidia were produced (Holm et al. 2003). In a few instances, early blight-symptomatic tubers were also submitted to our laboratory by a third party. Symptomatic areas of tubers were cut into small, flat sections with a sterilized cutting knife, placed on $1.5 \%$ water agar media, and grown as described previously until conidia were produced. Following culture growth, a single conidium was transferred to solid clarified V8 media (Campbell's V8 juice, $100 \mathrm{ml} ; \mathrm{CaCO}_{3}, 1.5 \mathrm{~g}$; agar, $15 \mathrm{~g}$; and distilled water, $900 \mathrm{ml}$ ) amended with ampicillin $50 \mathrm{mg} / \mathrm{ml}$. Cultures were incubated under continuous fluorescent light for 7 to 10 days and examined for the presence of A. solani conidia (Pasche et al. 2004). Long-term storage of individual isolates was achieved by filling two small, screw-top centrifuge tubes per isolate with 4-mm-diameter plugs of media, with fungal mycelia and conidia excised using a sterilized cork borer (Fonseka and Gudmestad 2016). The loosely capped tubes containing plugs were placed within silica gel in a closed container for 2 to 3 days to remove moisture from the media; caps were then tightened and sealed with Parafilm, and the tubes were placed in an ultrafreezer at a temperature of $-80^{\circ} \mathrm{C}$.

DNA extraction. DNA was extracted from all isolates using a modified cetyltrimethylammonium bromide (CTAB) method (Mallik et al. 2014; Stewart and Via 1999). First, mycelia and spores were scraped from a 7-day-old culture of A. solani into an autoclaved mortar and ground to fine powder with liquid nitrogen. Approximately $100 \mathrm{mg}$ of powder was transferred immediately into a tube of lysing matrix A (MP Biomedicals) consisting of $750 \mu \mathrm{l}$ of Carlson lysis buffer (100 mM Tris HC1 [pH 9.5], 2\% CTAB, 1.4 M NaCl, 1\% PEG 8000 , and $20 \mathrm{mM}$ EDTA) supplemented with $2 \% \beta$-mercaptoethanol. The tube was placed in a FastPrep instrument (MP Biomedicals) and subjected to agitation at a speed of $6.00 \mathrm{~m} / \mathrm{s}$ for $40 \mathrm{~s}$ to facilitate the homogenization of the mycelia and spore mixture. The sample was incubated in the tube at $75^{\circ} \mathrm{C}$ for $40 \mathrm{~min}$ with inversions at intervals of 10 to $15 \mathrm{~min}$ followed by a centrifugation at a speed of $14,000 \times \mathrm{g}$ for $10 \mathrm{~min}$ (Mallik et al. 2014). The supernatant was removed and placed immediately into a new tube. Nucleic acids were extracted in the aqueous phase by adding an equal volume of phenol/chloroform/isoamyl alcohol (25:24:1 [vol/vol]; Sigma-Aldrich). Genomic DNA was then precipitated with an equal volume of isopropanol and washed with $95 \%$ ethanol. Finally, the genomic DNA was reconstituted in

Table 1. Origin, fields sampled, and collection year for Alternaria solani isolates characterized for presence or absence of mutations associated with succinate dehydrogenase inhibiting and quinone outside inhibiting resistance

\begin{tabular}{|c|c|c|c|c|c|c|c|c|c|c|}
\hline \multirow[b]{2}{*}{ State } & \multicolumn{2}{|c|}{$2011^{a}$} & \multicolumn{2}{|c|}{2013} & \multicolumn{2}{|c|}{2014} & \multicolumn{2}{|c|}{2015} & \multicolumn{2}{|c|}{ Total } \\
\hline & Fields & Isolates & Fields & Isolates & Fields & Isolates & Fields & Isolates & Fields & Isolates \\
\hline Colorado & 2 & 2 & 14 & 80 & 0 & 0 & 5 & 26 & 21 & 108 \\
\hline Idaho & 17 & 19 & 1 & 1 & 4 & 17 & 1 & 3 & 23 & 40 \\
\hline Illinois & 0 & 0 & 12 & 19 & 0 & 0 & 0 & 0 & 12 & 19 \\
\hline Michigan & 0 & 0 & 1 & 16 & 1 & 16 & 0 & 0 & 2 & 32 \\
\hline Minnesota & 12 & 12 & 8 & 51 & 8 & 38 & 20 & 181 & 48 & 282 \\
\hline Nebraska & 18 & 18 & 11 & 47 & 7 & 58 & 14 & 138 & 50 & 261 \\
\hline New Mexico & 0 & 0 & 10 & 37 & 0 & 0 & 0 & 0 & 10 & 37 \\
\hline North Dakota & 10 & 10 & 30 & 83 & 11 & 80 & 6 & 70 & 57 & 243 \\
\hline Texas & 6 & 6 & 13 & 86 & 18 & 86 & 13 & 129 & 50 & 307 \\
\hline Washington & 0 & 0 & 1 & 6 & 0 & 0 & 0 & 0 & 1 & 6 \\
\hline Wisconsin & 0 & 0 & 3 & 40 & 0 & 0 & 1 & 15 & 4 & 55 \\
\hline Total & 65 & 67 & 104 & 466 & 49 & 295 & 60 & 562 & 278 & 1,390 \\
\hline
\end{tabular}

${ }^{\mathrm{a}}$ Data for 2011 to 2012 from Mallik et al. (2014). 
glass-distilled RNA-ase-DNAase-free water (Teknova Inc.) at a final concentration of $10 \mathrm{ng} \mathrm{l}^{-1}$, and RNA-ase $(0.2 \mu \mathrm{g})$ (Qiagen Inc.) was added.

Molecular detection of SDHI-resistant isolates. SDHI mutations were detected using previously described polymerase chain reaction (PCR) methods (Mallik et al. 2014). Mismatch amplification analysis (MAMA) primers previously developed were used to distinguish two mutations in the $A s S d h B$ gene. Amplification with MAMAB1-F and MAMABM-R primers, developed for isolates with the H278R mutation, yielded a 127-bp amplification product on agarose gel (Table 2). Amplification with the MAMAB1-F and MAMABR-R primers, developed for isolates possessing the $\mathrm{H} 278 \mathrm{Y}$ mutation, yields a 127-bp amplification product. However, isolates possessing a mutation associated with SDHI resistance in either the AsSdhC or $A s S d h D$ gene show no amplification bands in either the H278R or H278Y MAMA-PCR. For detection of these mutations, additional PCR assays are needed. Single-nucleotide polymorphisms (SNP) in AsSdhC and AsSdhD genes confer the H134R and H133R, respectively, and are amplified as part of a multiplex PCR assay previously developed (Table 2). A 235-bp amplification product along with either a 457-bp product or a 72-bp product were amplified if a mutation existed in $A s S d h C$ or $A s S d h D$ genes, respectively. A single amplification product with a 235-bp product alone confirmed that an isolate did not possess any of the mutations in the $A s S d h B, A s S d h C$, or $A s S d h D$ genes. The absence of any amplification product in the multiplex PCR assay indicated that there is a possible mutation in the $A s S d h B$ gene, and this was tested with the previously described MAMA-PCR assay (Table 2). MAMA-PCR assays were performed using a $25-\mu l$ volume consisting of $20 \mathrm{ng}$ of DNA, $1.5 \mathrm{mM} \mathrm{MgCl} 2,0.2 \mathrm{mM} \mathrm{dNTP}$, $5 \mu \mathrm{M}$ each primer, and $1 \mathrm{U}$ of Go Taq polymerase (Promega Corp.). Multiplex PCR also consisted of $25 \mu \mathrm{l}$, with $20 \mathrm{ng}$ of DNA, $2 \mathrm{mM}$ $\mathrm{MgCl}_{2}, 0.2 \mathrm{mM}$ dNTP, $5 \mu \mathrm{M}$ SdhBSen-F, $5 \mu \mathrm{M}$ SdhBSen-R, $3 \mu \mathrm{M}$ SdhC-F, $3 \mu \mathrm{M}$ SdhC-R1, $5 \mu \mathrm{M}$ SdhD-F, and $5 \mu \mathrm{M}$ SdhD$\mathrm{R} 1$ primers, followed by $1 \mathrm{U}$ of Go Taq polymerase (Promega Corp.). The MAMA-PCR was performed in a Peltier thermal cycler, DNA engine (Bio-Rad), with an initial preheat step of $95^{\circ} \mathrm{C}$ for $2 \mathrm{~min}$ followed by 30 cycles of denaturation at $95^{\circ} \mathrm{C}$ for $30 \mathrm{~s}$, annealing at $60^{\circ} \mathrm{C}$ for $30 \mathrm{~s}$, and extension at $72^{\circ} \mathrm{C}$ for $1 \mathrm{~min}$. A final extension at $72^{\circ} \mathrm{C}$ for 7 min was also added at the end of the program. The multiplex PCR program for amplifying $A s S d h C$ or $A s S d h D$ mutations was the same as above, except an annealing temperature of $58^{\circ} \mathrm{C}$ was used.

An additional PCR assay was then conducted with isolates that did not amplify in either of the previously discussed multiplex or
MAMA-PCR tests. Sequencing of the $A s S d h D$ gene of a single isolate collected in a previous study that did not amplify in PCR tests described above revealed a predicted aspartate (D, codon GAC) to glutamic acid (E, codon GAA) substitution in AsSdhD at amino acid position 123 (Mallik et al. 2014). Based on sequencing data, primers were designed using Primer 3 Plus software (www.bioinformatics. $\mathrm{nl}$ ). The PCR was performed in a thermal cycler DNA engine (Bio$\mathrm{Rad}$ ), consisting of an initial preheat step of $95^{\circ} \mathrm{C}$ for $2 \mathrm{~min}$; followed by 30 cycles of denaturation at $95^{\circ} \mathrm{C}$ for $30 \mathrm{~s}$, annealing at $60^{\circ} \mathrm{C}$ for $30 \mathrm{~s}$, and extension at $72^{\circ} \mathrm{C}$ for $1 \mathrm{~min}$; with a final extension at $72^{\circ} \mathrm{C}$ for $7 \mathrm{~min}$; and performed using a $23-\mu \mathrm{l}$ volume consisting of $20 \mathrm{ng}$ of DNA, $1.5 \mathrm{mM} \mathrm{MgCl} 2,0.5 \mathrm{mM}$ dNTP, $5 \mu \mathrm{M}$ each primer, and $1 \mathrm{U}$ of Go Taq polymerase (Promega Corp.). Isolates that yielded a 127-bp amplification product with this reaction possess the D123E mutation (Table 2). All amplified products were separated by gel electrophoresis in 1.2\% agarose gel (Mallik et al. 2014).

Detection of the F129L mutation. A real-time PCR-hybridization assay was used to detect the single-base-pair F129L mutation associated with reduced sensitivity to QoI fungicides in A. solani (Pasche et al. 2005). The PCR was carried out using the LightCycler thermocycler (Roche) in glass capillaries in a final volume of $20 \mathrm{ml}$ containing $1 \times$ FastStart DNA Master Hybridization Probes (Roche), $2 \mathrm{mM} \mathrm{MgCl}_{2}$ (Roche), $0.5 \mu \mathrm{M}$ AS-5F forward primer, $2.5 \mu \mathrm{M}$ AS-5R reverse primer, $0.2 \mu \mathrm{M}$ sensor (Asol-FL) and anchor (Asol-R640) probes, and $1 \mathrm{ng}$ of DNA. After an initial denaturation step of $95^{\circ} \mathrm{C}$ for $10 \mathrm{~min}, \mathrm{PCR}$ was run for 45 cycles using the following conditions: denaturation $\left(95^{\circ} \mathrm{C}, 10 \mathrm{~s}\right.$, ramp rate $\left.20^{\circ} \mathrm{C} / \mathrm{s}\right)$, annealing $\left(58\right.$ to $50^{\circ} \mathrm{C}, 10 \mathrm{~s}$, ramp rate $20^{\circ} \mathrm{C} / \mathrm{s}$, step size $1^{\circ} \mathrm{C}$, acquisition mode: single), and extension $\left(72^{\circ} \mathrm{C}, 8 \mathrm{~s}\right.$, ramp rate $\left.5^{\circ} \mathrm{C} / \mathrm{s}\right)$. After amplification, melting curves were generated at $95^{\circ} \mathrm{C}\left(10 \mathrm{~s}\right.$, ramp rate $\left.20^{\circ} \mathrm{C} / \mathrm{s}\right), 45^{\circ} \mathrm{C}(30 \mathrm{~s}$, ramp rate $\left.20^{\circ} \mathrm{C} / \mathrm{s}\right)$, and $85^{\circ} \mathrm{C}\left(0 \mathrm{~s}\right.$, ramp rate $0.1^{\circ} \mathrm{C} / \mathrm{s}$, acquisition mode: continuous). After a final cooling step for $30 \mathrm{~s}$ at $40^{\circ} \mathrm{C}$, melting curve analysis was performed. The real-time method includes amplification of a fragment of the cytochrome $b$ gene coupled with simultaneous detection of the product by probe hybridization and analysis of the melting point of the DNA fragments. The sensor probe in the assay is designed to span the mutation site so that the single-nucleotide mismatch position is at least $3 \mathrm{bp}$ away from the sensor probe end. When the sensor probe is melted away from the amplification product, the matching probe-target DNA will separate at a higher melting point temperature than probes that are bound to DNA which contain destabilizing nucleotide mismatches. A specific melting-point temperature can be obtained for each isolate in this manner (Pasche et al. 2005). As assessed, if the highest

Table 2. Mutations associated with resistance to succinate dehydrogenase inhibiting (SDHI) and quinone outside inhibiting (QoI) fungicides in Alternaria solani and primers used for their molecular detection

\begin{tabular}{|c|c|c|c|c|c|c|}
\hline \multirow[b]{2}{*}{ Mutation } & \multirow[b]{2}{*}{ Target } & \multirow[b]{2}{*}{ Primer name $^{\mathbf{a}}$} & \multirow[b]{2}{*}{ Sequence $\left(5^{\prime}-3^{\prime}\right)$} & \multirow[b]{2}{*}{$\mathbf{P C R}^{\mathbf{b}}$} & \multicolumn{2}{|c|}{ Resistance } \\
\hline & & & & & SDHI $^{c}$ & QoI $^{\mathbf{d}}$ \\
\hline \multirow[t]{2}{*}{$\mathrm{H} 278 \mathrm{Y}$} & $A s S d h B$ & MAMAB1-F & Mallik et al. 2014 & MAMA PCR & $\mathrm{B}^{\mathrm{VH}} \mathrm{P}^{\mathrm{H}} \mathrm{F}^{\mathrm{S}}$ & $S$ \\
\hline & $A s S d h B$ & MAMABR-R & Mallik et al. 2014 & MAMA PCR & & $\ldots$ \\
\hline \multirow[t]{2}{*}{$\mathrm{H} 278 \mathrm{R}$} & $A s S d h B$ & MAMAB1-F & Mallik et al. 2014 & MAMA PCR & $\mathrm{B}^{\mathrm{M}} \mathrm{P}^{\mathrm{M}} \mathrm{F}^{\mathrm{S}}$ & $S$ \\
\hline & $A s S d h B$ & MAMABM-R & Mallik et al. 2014 & MAMA PCR & & $\ldots$ \\
\hline \multirow[t]{2}{*}{ H134R } & AsSdhC & SdhC-F & Mallik et al. 2014 & Sdh multiplex & $\mathrm{B}^{\mathrm{VH}} \mathrm{P}^{\mathrm{VH}} \mathrm{F}^{\mathrm{S}}$ & S \\
\hline & AsSdhC & SdhC-R1 & Mallik et al. 2014 & Sdh multiplex & $\ldots$ & $\ldots$ \\
\hline \multirow[t]{2}{*}{ H133R } & $A s S d h D$ & SdhD-F & Mallik et al. 2014 & Sdh multiplex & $\mathrm{B}^{\mathrm{H}} \mathrm{P}_{\mathrm{MS}}$ & $\mathrm{S}$ \\
\hline & $A s S d h D$ & SdhD-R1 & Mallik et al. 2014 & Sdh multiplex & & $\ldots$ \\
\hline \multirow[t]{2}{*}{ D123E } & $A s S d h D$ & D123E-F & GCCCCAGAAGATCATCGGAA & MAMA PCR & $\mathrm{B}^{\mathrm{VH}} \mathrm{P}^{\mathrm{H}} \mathrm{F}^{\mathrm{S}}$ & S \\
\hline & As $S d h D$ & D123E-R1 & GAAGAGCGCATAGGATGGATCC & MAMA PCR & & $\cdots$ \\
\hline \multirow[t]{4}{*}{ F129L } & $C y t b$ & AS-5F & Pasche et al. 2005 & Real-time PCR & $\mathrm{B}^{\mathrm{S}} \mathrm{P}^{\mathrm{S}} \mathrm{F}^{\mathrm{S}}$ & M \\
\hline & Cytb & AS-5R & Pasche et al. 2005 & Real-time PCR & $\ldots$ & $\ldots$ \\
\hline & $C y t b$ & Sensor-Asol-FL & Pasche et al. 2005 & Real-time PCR & $\ldots$ & $\ldots$ \\
\hline & Cytb & Anchor-AsolR640 & Pasche et al. 2005 & Real-time PCR & $\ldots$ & $\ldots$ \\
\hline
\end{tabular}

a Primers used for detection of the H278Y, H278R, H134R, and H133R mutations were described by Mallik et al. (2014). Primers for the detection of the D123E mutation are described in this study.

${ }^{\mathrm{b}} \mathrm{PCR}=$ polymerase chain reaction and MAMA $=$ mismatch amplification analysis

${ }^{c}$ Resistance to SDHI fungicides boscalid (B), Penthiopyrad (P), and Fluopyram (F). S = sensitive (50\% effective concentration $\left.\left[\mathrm{EC}_{50}\right]<5 \mu \mathrm{g} / \mathrm{ml}\right), \mathrm{M}=\mathrm{moderate}$ resistance $\left(\mathrm{EC}_{50}=5\right.$ to $\left.20 \mu \mathrm{g} / \mathrm{ml}\right), \mathrm{H}=$ high resistance $\left(\mathrm{EC}_{50}\right.$ values $=20.1$ to $\left.100 \mu \mathrm{g} / \mathrm{ml}\right)$, and $\mathrm{VH}=$ very high resistance $\left(\mathrm{EC}_{50}=>100 \mu \mathrm{g} / \mathrm{ml}\right)$.

${ }^{\mathrm{d}} \mathrm{S}=$ sensitive and $\mathrm{M}=$ moderate resistance (12- to 15 -fold reduction in sensitivity to QoI fungicides). 
melting point temperature for the isolate is below $55^{\circ} \mathrm{C}$, the DNA fragment of the isolate possesses the F129L mutation and, thus, the isolate has reduced sensitivity to QoI. If the highest melting point is above $55^{\circ} \mathrm{C}$, it is regarded as the wild type.

Genotype characterization. Each A. solani isolate collected was also characterized for genotype I or genotype II, differing by the presence or absence of an intron in the cytb gene (Leiminger et al. 2014). Standard PCR was performed for the characterization of each genotype in a thermal cycler DNA engine, with an initial preheat step of $98^{\circ} \mathrm{C}$ for $2 \mathrm{~min}$; followed by 30 cycles of denaturation at $98^{\circ} \mathrm{C}$ for $10 \mathrm{~s}$, annealing at $54^{\circ} \mathrm{C}$ for $30 \mathrm{~s}$, and extension at $72^{\circ} \mathrm{C}$ for $10 \mathrm{~s}$; with a final extension at $72{ }^{\circ} \mathrm{C}$ for $5 \mathrm{~min}$; and performed using a $23-\mu \mathrm{l} \mathrm{vol-}$ ume consisting of $20 \mathrm{ng}$ of DNA, $1 \mathrm{mM} \mathrm{MgCl} 2,0.5 \mathrm{mM}$ dNTP, $5 \mu \mathrm{M}$ each primer, and $1 \mathrm{U}$ of Go Taq polymerase (Promega Corp.). The reaction was the same for the detection of both genotypes except for the primers used. For the detection of genotype I, the forward primer As-Gf and the reverse primer As-Gr, were used, yielding a 214-bp amplification product if the isolate possessed genotype I (Leiminger et al. 2014). For the detection of genotype II, the forward primer As-5f and reverse primer As-5r were used (Pasche et al. 2005). All amplified products were separated by gel electrophoresis in $1.2 \%$ agarose gel. For genotype II, a 207-bp fragment was amplified and, for genotype I, a 214-bp fragment was amplified (Leiminger et al. 2014).

Statistical analysis. Log-linear analysis was used to analyze categorical data (Jiménez-Díaz et al. 2011). Two categories were used: (i) year: 2011, 2013, 2014, or 2015; and (ii) state: North Dakota, Minnesota, Nebraska, Texas, Colorado, Wisconsin, New Mexico, Washington,
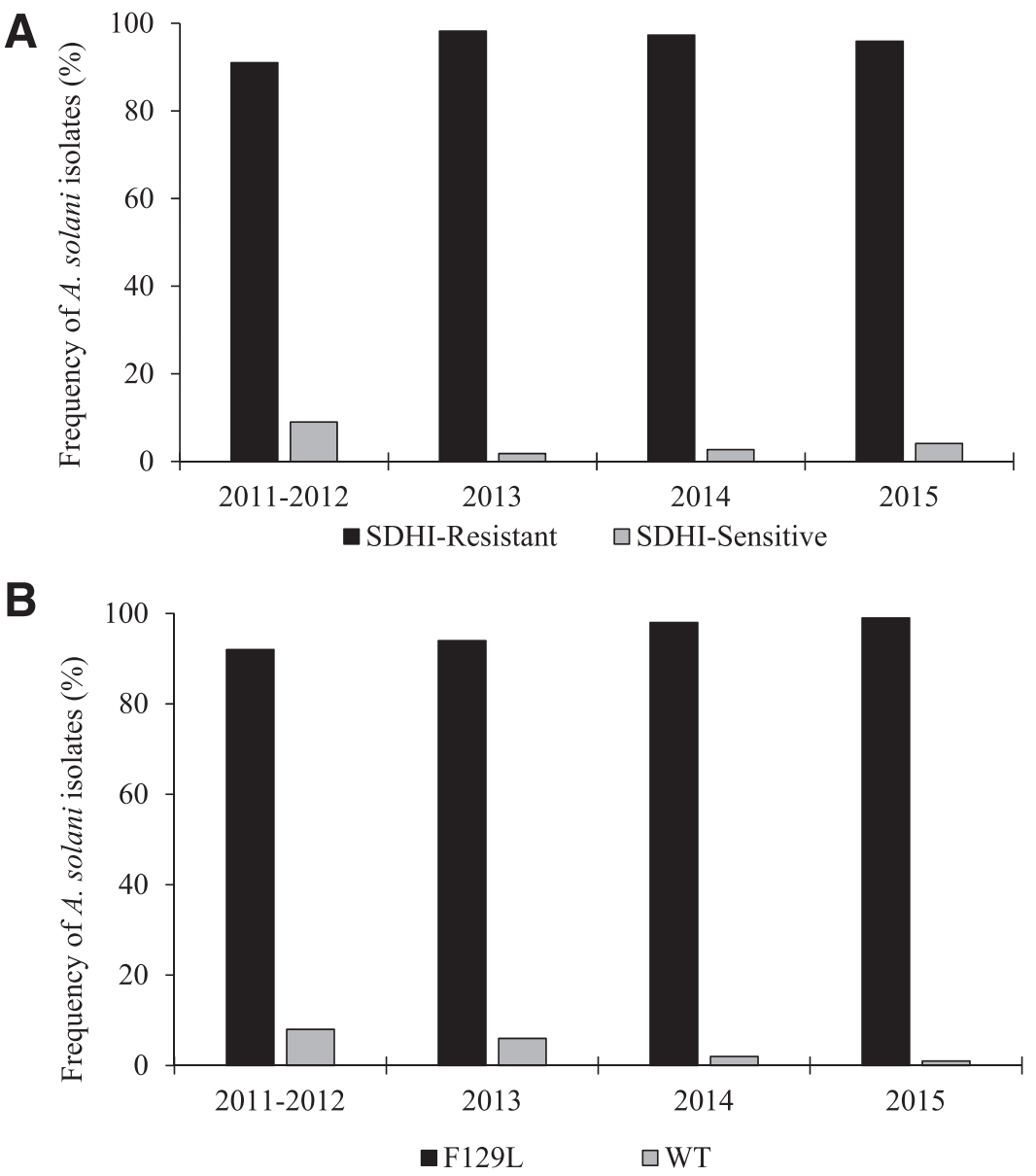

Fig. 1. Temporal frequency distribution of Alternaria solani isolates possessing $\mathbf{A}$, one of five mutations conferring resistance to succinate dehydrogenase inhibiting (SDHI) fungicides and $\mathbf{B}$, the F129L mutation conferring resistance to quinone outside inhibiting fungicides. SDHI-sensitive isolates were characterized as possessing none of the five known mutations. Wild-type (WT) isolates do not possess the F129L mutation. Data for 2011 to 2012 from Mallik et al. (2014).

Table 3. Maximum-likelihood analysis of variance from log-linear analysis for the effects of year and state on the frequency of mutations conferring resistance to succinate dehydrogenase inhibiting (SDHI) and quinone outside inhibiting (QoI) fungicides ${ }^{\mathrm{a}}$

\begin{tabular}{|c|c|c|c|c|c|c|c|c|c|}
\hline \multirow[b]{2}{*}{ Mutation } & \multicolumn{3}{|c|}{ Year } & \multicolumn{3}{|c|}{ State } & \multicolumn{3}{|c|}{ Year-state } \\
\hline & df & $\chi^{2}$ & $P>x^{2}$ & df & $x^{2}$ & $P>x^{2}$ & df & $\chi^{2}$ & $P>x^{2}$ \\
\hline $\mathrm{H} 278 \mathrm{Y}^{\mathrm{b}}$ & 3 & 193.09 & $<0.0001$ & 9 & 87.80 & $<0.0001$ & 12 & 46.05 & $<0.0001$ \\
\hline $\mathrm{H} 278 \mathrm{R}^{\mathrm{b}}$ & 3 & 20.20 & 0.0002 & 8 & 29.88 & 0.0002 & 7 & 14.41 & 0.0444 \\
\hline $\mathrm{H} 134 \mathrm{R}^{\mathrm{b}}$ & 3 & 51.71 & $<0.0001$ & 8 & 103.09 & $<0.0001$ & 8 & 33.65 & $<0.0001$ \\
\hline $\mathrm{H} 133 \mathrm{R}^{\mathrm{b}}$ & 3 & 36.34 & $<0.0001$ & 9 & 52.04 & $<0.0001$ & 8 & 61.31 & $<0.0001$ \\
\hline $\mathrm{D} 123 \mathrm{E}^{\mathrm{b}}$ & 3 & 24.67 & $<0.0001$ & 5 & 13.50 & 0.0191 & 5 & 6.68 & 0.2459 \\
\hline $\mathrm{F} 129 \mathrm{~L}^{\mathrm{c}}$ & 3 & 96.46 & $<0.0001$ & 10 & 597.57 & $<0.0001$ & 17 & 334.27 & $<0.0001$ \\
\hline
\end{tabular}

${ }^{a} P$ significant if $P<0.05$.

${ }^{\mathrm{b}}$ Mutation confers resistance to SDHI fungicides.

${ }^{\mathrm{c}}$ Mutation confers resistance to QoI fungicides. 
Michigan, Illinois, or Idaho. The CATMOD procedure in SAS software (Statistical Analysis System, version 9.3; SAS Institute) with log link was used. PROC CATMOD also provided estimates of maximumlikelihood for the main effects of year and state. A $\chi^{2}$ test was used to determine whether the frequency of mutations associated with QoI and SDHI resistance differed between states and years.

\section{Results}

Determination of overall prevalence of mutations conferring SDHI and QoI resistance. The percentage of $A$. solani isolates possessing mutations conferring SDHI resistance ranged from 90 to $99 \%$ across all years surveyed (Fig. 1A). Overall frequency of SDHIresistant isolates increased from $91 \%$ in 2011 to 2012 to above $96 \%$ in each of the last 3 years of the survey from 2013 through 2015. The percentage of SDHI-sensitive isolates, or $A$. solani isolates found to possess none of the five characterized mutations on the three AsSdh genes, ranged from $9 \%$ in 2011 to $<1 \%$ in 2015. Similarly, A. solani isolates possessing the F129L mutation conferring resistance to QoI fungicides were also dominant throughout all four years of collection (Fig. 1B). In 2011 to 2012, the percentage of isolates possessing the F129L mutation was $92 \%$, whereas $99 \%$ of the isolates collected in 2015 possessed this QoI mutation. Overall, the frequency of $A$. solani isolates possessing mutations conferring $\mathrm{QoI}$ and $\mathrm{SDHI}$ resistance was higher in each of the last 3 years of collection compared with the frequencies observed in 2011 to 2012 (Mallik et al. 2014). Furthermore, $99 \%$ of $A$. solani isolates possessing one of the five possible mutations conferring SDHI resistance collected each year concurrently possess the F129L mutation conferring QoI resistance, indicating that isolates resistant to both chemical classes predominate in the A. solani population sampled across the United States.

Determination of temporal frequency distribution of mutations conferring QoI and SDHI resistance in A. solani. Loglinear analysis determined that collection year had a significant effect $(P=0.05)$ on the frequencies of mutations conferring SDHI and QoI resistance (Table 3). Collection year had a significant effect $\left(\chi^{2}=96.46, P<0.0001\right)$ on the frequency of F129L-mutant $A$. solani isolates collected and there was a significant year-state interaction $\left(\chi^{2}=334.27, P<0.0001\right)$ (Table 3$)$. Collection year also had a significant effect on the frequency of $A$. solani isolates possessing the H278Y or H278R mutation on the $A s S d h B$ gene conferring SDHI resistance $\left(\chi^{2}=193.09\right.$ and $20.20 ; P<0.0001$ and $P=0.0002$, respectively). In addition, there was also a significant year-state interaction that significantly affected the frequency of both mutations. Similarly, collection year had a significant effect on the frequency of $A$. solani isolates possessing the H134R mutation on the AsSdhC gene or the H133R mutation on the AsSdhD gene ( $\chi^{2}=51.71$ and 36.34; $P<$ 0.0001 and 0.0001 , respectively). A significant year-state interaction

Table 4. Analysis of maximum-likelihood estimates from log-linear analysis for the main effects of year on frequency of mutations conferring resistance to succinate dehydrogenase inhibiting (SDHI) and quinone outside inhibiting (QoI) fungicides among years

\begin{tabular}{lrrr}
\hline Mutation & Year & Estimate & $\boldsymbol{P}>\boldsymbol{x}^{\mathbf{2 a}}$ \\
\hline H278Y $^{\mathrm{b}}$ & 2013 & -0.5942 & $<0.0001$ \\
& 2014 & 0.4038 & $<0.0001$ \\
& 2015 & 1.1328 & $<0.0001$ \\
H278R $^{\mathrm{b}}$ & 2013 & 0.8577 & $<0.0001$ \\
& 2014 & -0.3273 & 0.3408 \\
& 2015 & -0.8326 & 0.0303 \\
H134R $^{\mathrm{b}}$ & 2013 & 0.9093 & $<0.0001$ \\
& 2014 & 0.2611 & 0.0856 \\
& 2015 & 0.5038 & 0.0005 \\
H133R $^{\mathrm{b}}$ & 2013 & -0.1234 & 0.3773 \\
& 2014 & 0.0164 & 0.9063 \\
& 2015 & 0.7549 & $<0.0001$ \\
D123E $^{\mathrm{b}}$ & 2013 & 0.0098 & 0.9758 \\
& 2014 & 0.3283 & 0.2892 \\
& 2015 & 1.1850 & $<0.0001$ \\
F129L $^{\mathrm{c}}$ & 2013 & -0.1732 & $<0.0001$ \\
& 2014 & -0.3180 & $<0.0001$ \\
& 2015 & 0.2601 & $<0.0001$ \\
\hline
\end{tabular}

a Significant if $P<0.05$.

${ }^{\mathrm{b}}$ Mutation confers resistance to SDHI fungicides.

c Mutation confers resistance to QoI fungicides.
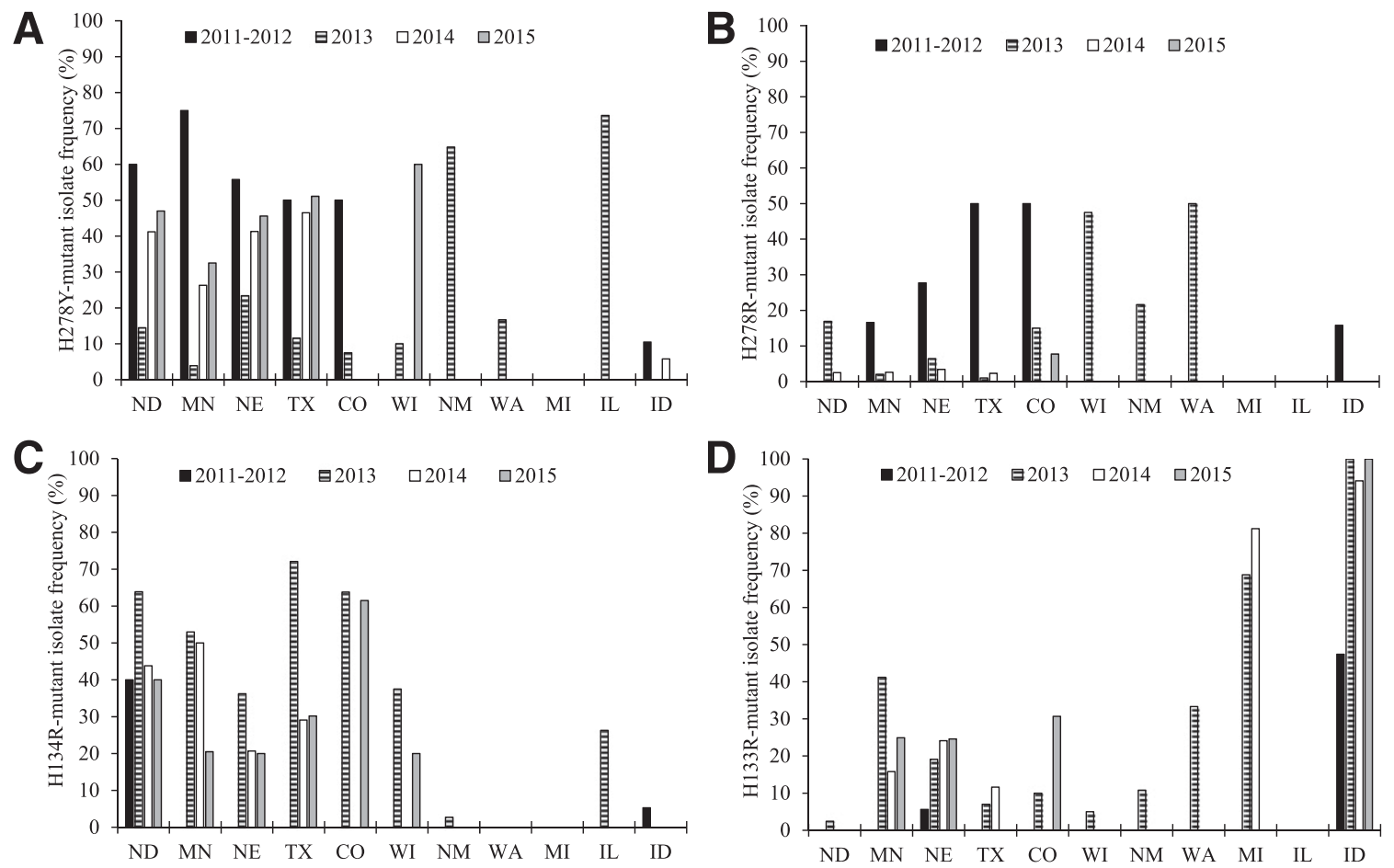

Fig. 2. Frequency of Alternaria solani isolates in each state possessing $\mathbf{A}$, the $\mathrm{H} 278 \mathrm{Y}$ mutation on $A s S d h B ; \mathbf{B}$, the $\mathrm{H} 278 \mathrm{R}$ mutation on AsSdhB; $\mathbf{C}$, the H134R mutation on the AsSdhC; and D, the H133R mutation on the AsSdhD each year of collection in North Dakota (ND), Minnesota (MN), Nebraska (NE), Texas (TX), Colorado (CO), Wisconsin (WI), New Mexico (NM), Washington (WA), Michigan (MI), Illinois (IL), and Idaho (ID). Data for 2011 to 2012 from Mallik et al. (2014). 
was observed also, suggesting that the combination of year and state had a significant effect on the frequency of these mutations. However, although collection year had a significant effect on the frequency of the D123E mutation in the isolates collected $\left(\chi^{2}=24.67, P<0.0001\right)$, there was no significant year-state interaction $\left(\chi^{2}=6.68, P=\right.$ 0.2459 ), indicating that year and state independently effected the frequency of isolates possessing the D123E mutation that were recovered (Table 3).

Analysis of maximum-likelihood estimates from log-linear analysis for the main effects of year and state on the frequency of mutations conferring QoI and SDHI resistance in A. solani determined that the probabilities of collecting mutant isolates were significantly different among years (Table 4). The probability of collecting H278Y-mutant A. solani isolates was significantly greater $(P<0.0001)$ in 2015 compared with 2013 or 2014, whereas the probability of collecting H278R mutants was significantly lower $(P<0.0001)$ in 2015 and 2014 compared with 2013. The probabilities of collecting A. solani isolates possessing the H134R mutation on the AsSdhC gene were the highest in 2013 and $2015(P<0.0001$ and $P=0.0005$, respectively). H133R- and D123E-mutant $A$. solani isolates had significantly higher probability of detection in 2015 compared with other years $(P<0.0001)$ (Table 4$)$. Similarly, the probability of recovering F129L-mutant $A$. solani isolates was significantly higher in 2015 compared with other years of the survey $(P<0.0001)$ (Table 4$)$.

The frequency of $A$. solani isolates possessing mutations conferring SDHI resistance was significantly different among years according to a $\chi^{2}$ test $\left(\chi^{2}=211.6378, P<0.0001\right)$ (Fig. 2). From 2013 to
2015, A. solani isolates possessing mutations on the $A s S d h B$ gene were collected at lower frequencies compared with 2011 to 2012 (Fig. 2A; B). The frequency of $A$. solani isolates possessing the H278R mutation decreased over time (Fig. 2B). The frequency of H278Y-mutant $A$. solani isolates was dynamic from year to year, increasing from 2013 to 2015 (Fig. 2A). Despite this increase, A. solani isolates possessing the H278Y mutation were found at lower frequencies in 2013 to 2015 compared with 2011 to 2012 (Fig. 2A). From 2013 to 2015, the frequency of H134R-mutant $A$. solani isolates was higher compared with 2011 to 2012, comprising over $40 \%$ of isolates in a number of states, particularly in the Midwest (Fig. 2C). The frequencies of both H133Rand D123E-mutant isolates increased from 2013 to 2015 (Fig. 2D; Figure 2A). Interestingly, in 2011 to 2012, D123E-mutant isolates were $1.5 \%$ of isolates collected but made up 5, 10, and $12 \%$ of isolates collected in 2013, 2014, and 2015, respectively (Fig. 3A).

Determination of spatial frequency distribution of mutations conferring QoI and SDHI resistance in A. solani. Log-linear analysis also determined that the state where $A$. solani was collected had a significant effect $(P=0.05)$ on the frequencies of mutations conferring SDHI and QoI resistance (Table 3). The state where isolates were collected had a significant effect on the frequency of the F129L-mutant A. solani isolates $\left(\chi^{2}=597.57, P<0.0001\right)$ (Table 3$)$. State, or location of the isolate sample, also had a significant effect on the frequency of A. solani isolates possessing mutations on the $A s S d h B, A s S d h C$, and $A s S d h D$ genes. This means that, as a main effect, state was determined to be a significant factor for the frequency of the five mutations associated with SDHI resistance in A. solani isolates.
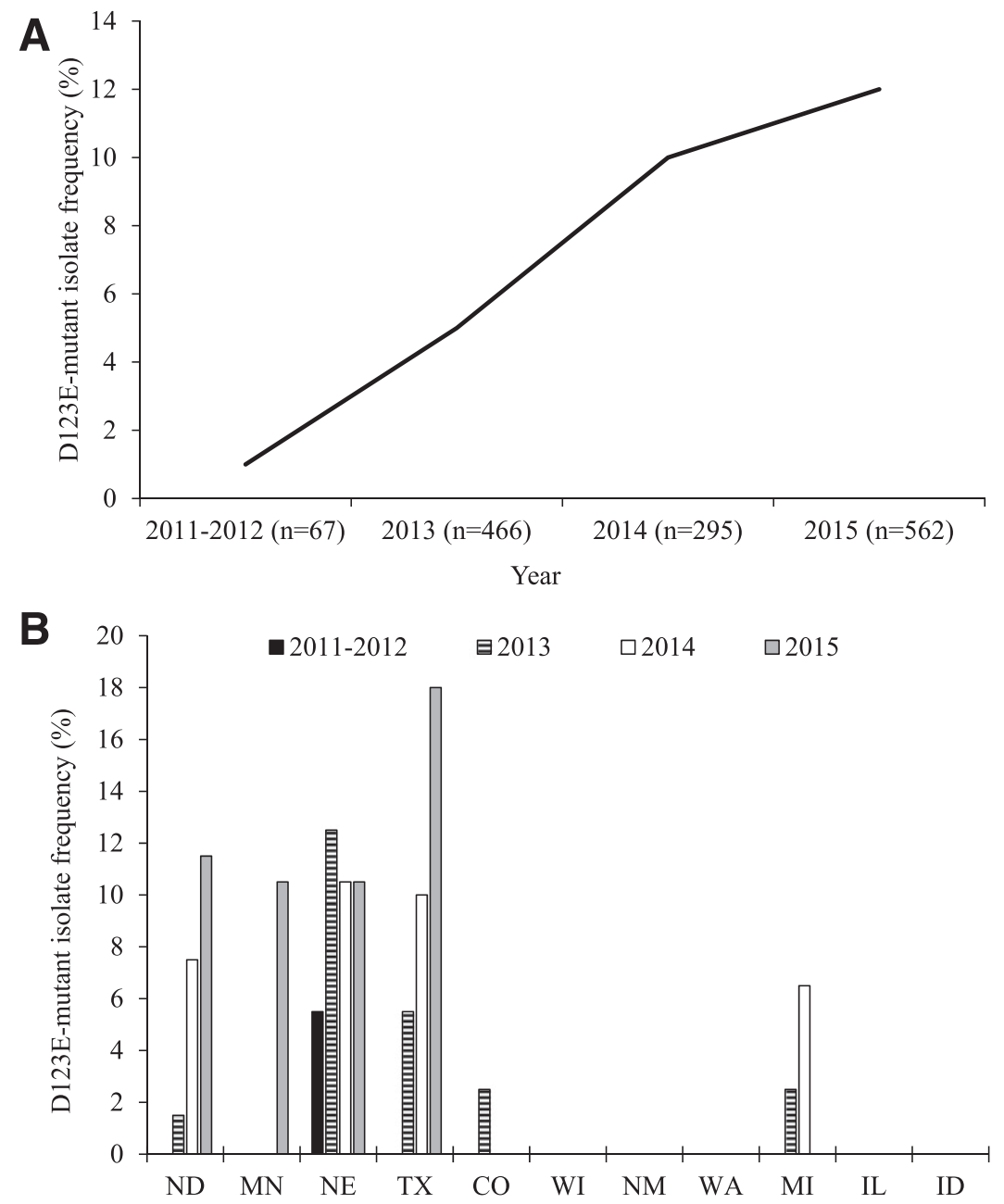

Fig. 3. A, Temporal and B, spatial frequency of Alternaria solani isolates possessing the D123E mutation on the AsSdhD gene conferring resistance to succinate dehydrogenase inhibiting fungicides in North Dakota (ND), Minnesota (MN), Nebraska (NE), Texas (TX), Colorado (CO), Wisconsin (WI), New Mexico (NM), Washington (WA), Michigan (MI), Illinois (IL), and Idaho (ID). Data for 2011 to 2012 from Mallik et al. (2014). 
Analysis of maximum-likelihood estimates from log-linear analysis for the main effects of year and state on the frequency of mutations conferring QoI and SDHI resistance in A. solani determined that the probabilities of collecting mutant isolates were significantly different among states (Table 5). It was determined that probability of collecting A. solani isolates with the F129L mutation was significantly higher in the states of North Dakota, Minnesota, Nebraska, Texas, Washington, Michigan, and Idaho. The probability of collecting A. solani isolates possessing the $\mathrm{H} 278 \mathrm{Y}$ mutation was the highest in the states of Minnesota, North Dakota, and Wisconsin $(P=$ $0.0227,0.0098$, and 0.0004 , respectively) (Table 5). Although detected in only a small percentage of total isolates collected in 2014 and 2015, the probability of recovering $\mathrm{H} 278 \mathrm{R}-$ mutant $A$. solani isolates was the greatest in Minnesota and Wisconsin $(P<0.0001$ and 0.0092 , respectively). The probability of identifying H134R-mutant isolates in the states of North Dakota, Minnesota, Colorado, and Texas was significantly higher than in other states $(P<0.0001)$ (Table 5). The states of Minnesota and Nebraska were determined to have significantly higher probabilities of recovering H133R-mutant isolates compared with other states. A. solani isolates possessing the D123E mutation on the $A s S d h D$ gene had a significantly higher probability of being collected in Texas $(P=0.0034)$ compared with other states (Table 5). The overall percentage of isolates collected possessing the D123E mutation increased over the years of the survey and were recovered at higher frequencies in North Dakota, Minnesota, Michigan, Colorado, Nebraska, and Texas from 2013 to 2015 (Fig. 3A and B).

The frequency of $A$. solani isolates possessing mutations conferring SDHI resistance was significantly different among states according to a $\chi^{2}$ test $\left(\chi^{2}=700.6578, P<0.0001\right)$ (Fig. 2). Mutant isolates possessing the $\mathrm{H} 278 \mathrm{Y}$ mutation on the $A s S d h B$ gene were collected at lower frequencies in North Dakota, Minnesota, Nebraska, and Colorado in 2011 but still made up a large percentage of isolates collected across those states in 2015, as well as in states not previously sampled in 2011 to 2012, including Wisconsin, New Mexico, Washington, and Illinois (Fig. 2A). Although identified in a large percentage of isolates in Texas, Colorado, and Idaho in 2011, A. solani isolates possessing the H278R mutation on the $A s S d h B$ gene decreased in frequency across all states from 2013 to 2015. In 2015, H278R-mutant isolates were detected as a small percentage of isolates obtained from Colorado and were not detected in isolates recovered from any other state (Fig. 2B). The frequency of $A$. solani isolates possessing the H134R mutation increased across a number of states relative to 2011, composing a high percentage of isolates collected across several states, including North Dakota, Minnesota, Nebraska, Texas, Colorado, and Wisconsin, in 2013 to 2015 (Fig. 2C). In 2011, only two states had A. solani isolates possessing the H133R mutation on the $A s S d h D$ gene. In the current study, the H133R mutation was detected in 10 of 11 states and represented nearly $100 \%$ of isolates collected from Idaho in 2013 to 2015 (Fig. 2D).

The frequency of $A$. solani isolates with the F129L mutation also was determined to be significantly different among states $\left(\chi^{2}=\right.$ 62.2367, $P<0.0001)$ as well as years $\left(\chi^{2}=81.1208, P<0.0001\right)$. Relative to 2011 to 2012, F129L-mutant $A$. solani isolates were collected at a greater frequency and made up a high percentage of isolates recovered across all 11 states from 2013 to 2015 (Fig. 4). Nearly 100\% of the isolates in North Dakota, Minnesota, Texas, Colorado, and Idaho possessed the F129L mutation conveying resistance to QoI fungicides (Fig. 4).

Prevalence of genotypes $I$ and $I I$ in a diverse population of A. solani isolates collected throughout the United States. The percentage of genotype II $A$. solani isolates was significantly higher than genotype I across all 11 states from which isolates were collected and across all years. In fact, over $99 \%$ of all isolates collected throughout the spatial-temporal survey were genotype II, with only a small percentage of $A$. solani isolates, less than $1 \%$ total, characterized as genotype I (data not shown).

\section{Discussion}

The research reported here demonstrates that mutations associated with SDHI and QoI resistance are prevalent in many potato production regions of the United States and that there is significant spatial and temporal variability in the distribution of these mutations. This is the first report of the frequencies of these mutations in a spatially and temporally diverse collection of $A$. solani isolates.

Resistance to QoIs in many fungi such as A. alternata, Cercospora beticola, B. cinerea, Ascochyta rabiei, and Venturia inaequalis is the result of an amino acid substitution of glycine with alanine at position 143 in the $c y t b$ gene $(\mathrm{G} 143 \mathrm{~A})$, which conveys a high level of resistance (Bardas et al. 2010; Bolton et al. 2013; Delgado et al. 2013; Frederick et al. 2014; Ma et al. 2003). However, resistance to QoIs in Alternaria solani has been attributed to the F129L mutation, or

Table 5. Analysis of maximum-likelihood estimates from log-linear analysis for differences in the frequency of mutations conferring resistance to succinate dehydrogenase inhibiting (SDHI) and quinone outside inhibiting (QoI) fungicides among states

\begin{tabular}{|c|c|c|c|}
\hline Mutation & State & Estimate & $P>x^{2 \mathrm{a}}$ \\
\hline \multirow[t]{9}{*}{$\mathrm{H} 278 \mathrm{Y}^{\mathrm{b}}$} & Colorado & -0.2701 & $\overline{0.4647}$ \\
\hline & Illinois & 0.9571 & 0.0009 \\
\hline & Minnesota & 0.3933 & 0.0227 \\
\hline & North Dakota & 0.4421 & 0.0098 \\
\hline & Nebraska & 0.6934 & $<0.0001$ \\
\hline & New Mexico & 1.4961 & $<0.0001$ \\
\hline & Texas & 0.7904 & $<0.0001$ \\
\hline & Washington & -1.6819 & 0.0642 \\
\hline & Wisconsin & -1.0077 & 0.0004 \\
\hline \multirow[t]{8}{*}{$\mathrm{H} 278 \mathrm{R}^{\mathrm{b}}$} & Colorado & 0.3670 & 0.1755 \\
\hline & Minnesota & -1.0215 & 0.0275 \\
\hline & North Dakota & 0.7290 & 0.0092 \\
\hline & Nebraska & -0.1052 & 0.7370 \\
\hline & New Mexico & 0.3026 & 0.3951 \\
\hline & Texas & -0.6160 & 0.1117 \\
\hline & Washington & -0.6782 & 0.2068 \\
\hline & Wisconsin & 1.1449 & $<0.0001$ \\
\hline \multirow[t]{8}{*}{$\mathrm{H} 134 \mathrm{R}^{\mathrm{b}}$} & Colorado & 0.8977 & $<0.0001$ \\
\hline & Illinois & -1.1867 & 0.0063 \\
\hline & Minnesota & 0.8389 & $<0.0001$ \\
\hline & North Dakota & 1.1737 & $<0.0001$ \\
\hline & Nebraska & 0.4454 & 0.0380 \\
\hline & New Mexico & -2.7962 & 0.0019 \\
\hline & Texas & 1.2564 & $<0.0001$ \\
\hline & Wisconsin & -0.4166 & 0.1294 \\
\hline \multirow[t]{9}{*}{$\mathrm{H} 133 \mathrm{R}^{\mathrm{b}}$} & Colorado & -0.0874 & 0.7505 \\
\hline & Idaho & 0.0943 & 0.6798 \\
\hline & Michigan & 0.7783 & 0.0011 \\
\hline & Minnesota & 1.1258 & $<0.0001$ \\
\hline & North Dakota & -0.9411 & 0.1485 \\
\hline & Nebraska & 0.7875 & $<0.0001$ \\
\hline & New Mexico & -0.2480 & 0.6005 \\
\hline & Texas & 0.3728 & 0.1682 \\
\hline & Washington & -0.9411 & 0.1485 \\
\hline \multirow[t]{5}{*}{$\mathrm{D} 123 \mathrm{E}^{\mathrm{b}}$} & Colorado & -0.5749 & 0.3597 \\
\hline & Michigan & -0.5236 & 0.2038 \\
\hline & North Dakota & -0.2852 & 0.2838 \\
\hline & Nebraska & 0.2648 & 0.2455 \\
\hline & Texas & 0.6177 & 0.0034 \\
\hline \multirow[t]{10}{*}{$\mathrm{F} 129 \mathrm{~L}^{\mathrm{c}}$} & Colorado & -0.0448 & 0.6672 \\
\hline & Idaho & -1.4365 & $<0.0001$ \\
\hline & Illinois & -0.3675 & 0.0898 \\
\hline & Michigan & -0.568 & 0.0014 \\
\hline & Minnesota & 1.2092 & $<0.0001$ \\
\hline & North Dakota & 0.7982 & $<0.0001$ \\
\hline & Nebraska & 0.9726 & $<0.0001$ \\
\hline & New Mexico & 0.2991 & 0.0635 \\
\hline & Texas & 1.1615 & $<0.0001$ \\
\hline & Washington & -1.5201 & $<0.0001$ \\
\hline
\end{tabular}

a Significant if $P<0.05$.

${ }^{\mathrm{b}}$ Mutation confers resistance to SDHI fungicides.

${ }^{\mathrm{c}}$ Mutation confers resistance to QoI fungicides. 
the substitution of phenylalanine with leucine at position 129 (Pasche et al. 2005), in the cytb gene. The F129L mutation conveys a moderate level of resistance to QoI fungicides such as azoxystrobin and pyraclostrobin, resulting in a 12- to 15 -fold reduction in sensitivity (Pasche and Gudmestad 2008; Pasche et al. 2005). Also within the $c y t b$ gene structure, two genotypes have been detected in A. solani, genotype I and genotype II (Leiminger et al. 2014). Sequence analysis revealed the occurrence of two structurally different $c y t b$ genes, which differed in the presence (genotype I) or absence (genotype II) of an intron. This study is the first to determine the prevalence of each A. solani genotype in the United States. In Germany A. solani isolates with the F129L mutation were identified only in genotype II A. solani; however, genotype I isolates were far more prevalent, occurring in $63 \%$ of the isolates collected (Leiminger et al. 2014). A much different scenario exists within the United States, where nearly $100 \%$ of isolates collected were characterized as genotype II, although the F129L mutation was found to occur in both genotypes. It has been speculated that the F129L substitution must have occurred independently in the United States and Germany and occurred at least twice in the United States because the F129L substitution was found in United States isolates of both genotypes (Leiminger et al. 2014).

Resistance to SDHI fungicides in A. solani was first detected when field isolates collected in 2009 and 2010 from Idaho were determined to be resistant to boscalid (Wharton et al. 2012). However, in the study by Wharton et al. (2012), A. solani isolates were reported as either completely resistant or completely sensitive to boscalid and 50\% effective concentration values were not reported. Further studies reported widespread resistance in A. solani to boscalid in a number of states (Gudmestad et al. 2013; Mallik et al. 2014), including Idaho (Fairchild et al. 2013). Another study identified four mutations in two AsSdh genes in isolates recovered in Idaho and determined to be resistant to boscalid in vitro (Miles et al. 2014). The H277R mutation in the $A s S d h B$ gene and the T28A, A47T, and H133R mutations in the $A s S d h D$ gene were detected in 7 of $11 \mathrm{~A}$. solani isolates evaluated in that study. Furthermore, many of these seven isolates were determined to possess more than one of these four mutations (Miles et al. 2014). Most studies of Alternaria spp. suggest that mutations associated with SDHI resistance independently confer resistance with only one mutation present in any single isolate (Avenot and Michailides 2010; Avenot et al. 2009; Mallik et al. 2014) and are in agreement with the results of the current studies reported here.

The previous study by our research group characterized a total of 67 A. solani isolates for the presence of mutations associated with SDHI resistance (Mallik et al. 2014). Mutations on the AsSdhB gene were not only the most commonly detected but were also demonstrated to be generally distributed among the six states of Colorado, Idaho, Minnesota, North Dakota, Nebraska, and Texas. This was determined to not be the case with mutations on the AsSdhC and $A s S d h D$ genes because isolates possessing these mutations were found to be more region specific (Mallik et al. 2014). Additionally, only a single isolate out of the 67 total that were characterized in the previous study was found to possess the D123E mutation on the $A s S d h D$ gene and was associated with high boscalid and penthiopyrad resistance (Mallik et al. 2014). Compared with the initial survey conducted in 2011 to 2012 by our lab, the results of this study using A. solani isolates collected from 2013 through 2015 suggest significant temporal shifts in the frequencies of each mutation. Mutations conferring SDHI resistance in the $A s S d h B$ gene were collected at a lower frequency while mutations on the $A s S d h C$ and $A s S d h D$ gene were collected at a higher frequency from 2013 to 2015 compared with the previous study. However, from 2013 to 2015, the H278Y mutation was detected in isolates collected from all states except Michigan and was still identified in more than $20 \%$ of $A$. solani isolates collected from states across the Midwest, including North Dakota, Minnesota, Nebraska, Texas, and Colorado. The H278R mutation was identified in significantly lower frequencies in 2013 through 2015 compared with 2011 , making up less than $1 \%$ of the 562 isolates collected in 2015 in contrast to $20 \%$ of the 67 isolates characterized in 2011 to 2012. The current survey in this study identified the H134R mutation on the $A s S d h C$ gene to be the most prevalent, with $36 \%$ of $A$. solani isolates collected possessing this mutation.

This study also suggests significant spatial variability in the mutations associated with SDHI resistance in A. solani. The main effects of collection year and state when the potato leaves were collected had a significant effect on the frequency of $A$. solani isolates possessing mutations conferring resistance to QoI and SDHI fungicides. Specifically, the combined effect of year and state also had a significant effect on the frequency of $A$. solani isolates possessing mutations associated with QoI and SDHI resistance, except those possessing the D123E mutation. A. solani isolates possessing mutations on the $A s S d h B$ gene were more prevalent in the states of North Dakota, Minnesota, and Wisconsin. However, A. solani isolates possessing the H134R mutation on the AsSdhC gene had a higher probability of being collected in Colorado and Texas, in addition to North Dakota and Minnesota. H133R-mutant isolates were more prevalent in Minnesota and Nebraska and, therefore, had a higher probability of being collected in those states relative to other locations around the United States. Finally, isolates possessing the D123E mutation

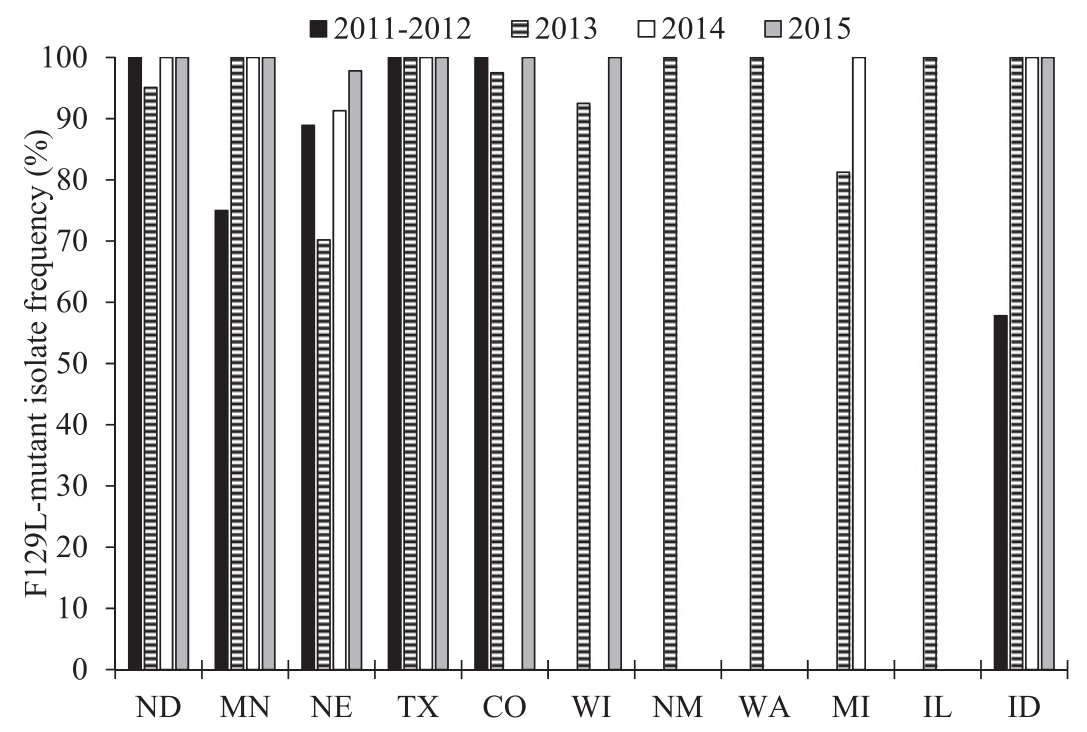

Fig. 4. Frequency of Alternaria solani isolates in each state possessing the $\mathrm{F} 129 \mathrm{~L}$ mutation conferring resistance to quinone outside inhibiting fungicides each year of collection in North Dakota (ND), Minnesota (MN), Nebraska (NE), Texas (TX), Colorado (CO), Wisconsin (WI), New Mexico (NM), Washington (WA), Michigan (MI), Illinois (IL), and Idaho (ID). Data for 2011 to 2012 from Mallik et al. (2014). 
on the $A s S d h D$ gene were detected at an increasingly higher frequency relative to isolates possessing other mutations associated with SDHI resistance development, and have the highest probability of being recovered in the state of Texas. Multiple states across the United States were found to have an $A$. solani population dominated by QoI resistance in $100 \%$ of the isolates collected from several of the 11 states included in this study. This suggests that an increasing percentage of isolates from $A$. solani populations across the country possess the F129L mutation relative to previous studies (Mallik et al. 2014; Pasche and Gudmestad 2008), suggesting that this mutation is stable in this fungal pathogen.

There are several possible reasons for our observed shift in frequencies of mutations conferring SDHI and QoI resistance in A. solani. This study involved the sampling of infected foliar and tuber tissue from 11 states. However, not all 11 states were sampled in each year and, in some states, large numbers of isolates were collected whereas, in other states, smaller numbers of isolates were collected. A previous study identified aggregation in the spatial distribution patterns of SNP related to fungicide resistance in $B$. cinerea, which has important implications for sample size and methods (Van der Heyden et al. 2014) and suggests that, if a pathogen population is aggregated, large sample sizes are required. Another possible reason for the shifts in spatial and temporal frequency of mutations presented here is the various levels of resistance to foliar fungicide chemistries of SDHIs and QoIs conveyed by the various identified mutations. For example, the H134R mutation in the $A s S d h C$ gene was observed most commonly in A. solani isolates with high levels of boscalid and penthiopyrad resistance. Similarly, the H133R and D123E mutations in the $A s S d h D$ gene were also observed in isolates with high levels of boscalid resistance. However, isolates possessing the $\mathrm{H} 278 \mathrm{Y}$ or H278R mutation in the $A s S d h B$ gene were associated with moderate levels of resistance to boscalid and penthiopyrad. The H278Y mutation was shown to be associated with high levels of boscalid resistance but only a moderate level of resistance to penthiopyrad, and the H278R mutation was shown to confer only moderate levels of resistance to both SDHI chemistries (Gudmestad et al. 2013; Mallik et al. 2014). Comparatively, these mutations confer differing levels of resistance to SDHI fungicides and mutations associated with resistance on the $A s S d h C$ and $A s S d h D$ genes consistently confer higher levels of resistance to boscalid and penthiopyrad than mutations on the $A s S d h B$ gene. Mutations identified conferring resistance to SDHI fungicides in $B$. cinerea were also shown to have differential effects because different mutations conveyed dissimilar sensitivities among the SDHI chemistries (Veloukas et al. 2011, 2013). Therefore, the results of this study may be due to selection for $A$. solani isolates possessing mutations conferring a higher level of resistance. Furthermore, because nearly $100 \%$ of $A$. solani isolates identified as possessing a mutation conferring SDHI resistance also possess the F129L mutation conveying QoI resistance, selection for multiple chemical classes is present in A. solani populations across the United States. This phenomenon of selection for resistance to multiple chemical classes at once, termed "selection by association", is based on the assumption that an isolate with resistance to multiple chemical classes would be selected by the application of any one those chemical classes (Hu et al. 2016). This indirect selection, or selection by association, could be a reason why A. solani isolates resistant to both SDHI and QoI fungicides are predominant across the country. It is also possible that fungicide-induced mutagenesis could be accelerating the genetic changes in field populations in $A$. solani and why we are observing an increase in the occurrence of these mutations associated with fungicide resistance within and between populations. However, this was previously investigated in Monilinia fructicola, where it was found that fungicide-induced genetic changes may not readily occur under field conditions (Dowling et al. 2016).

The most obvious reason for the shift in spatial and temporal frequency of mutations in A. solani associated with SDHI and QoI resistance, and a critical aspect in SDHI resistance development, is the existence of possible fitness penalties of target mutations (Kim and Xiao 2011; Scalliet et al. 2012; Sierotzki and Scalliet 2013). Previous studies with $A$. solani could not identify any fitness penalties associated with QoI resistance (Pasche and Gudmestad 2008). Similarly, no significant difference in predicted fitness was observed between A. alternata or A. solani isolates possessing mutations conferring SDHI resistance and wild-type isolates under the parameters of spore germination and mycelial growth in vitro (Landschoot et al. 2017). However, given the high prevalence of $A$. solani isolates possessing one of the five possible mutations conveying SDHI resistance accompanied with the F129L mutation conveying QoI resistance, further study comparing pathogenic fitness of wild-type versus mutant isolates is warranted. The existence of any significant fitness penalties in fungicide-resistant isolates of any pathogen can predict the efficacy of fungicide resistance management tactics such as tank-mixing in delaying or preventing the development of further resistance issues (Mikaberidze et al. 2014). The assessment of fitness costs of fungicide resistance mutations is crucial to determine whether fungicide mixtures select for resistance. Some studies have identified fitness costs in fungicide resistance pathogen populations in both laboratory and field settings (Iacomi-Vasilescu et al. 2008; Karaoglanidis et al. 2001). Specifically, a recent study of fitness of $B$. cinerea field isolates with dual SDHI and QoI resistance determined that isolates with mutations in the $B c S d h B$ gene may be adversely affected and that sensitive isolates dominated in the absence of fungicide selection pressure in competition experiments (Veloukas et al. 2014). Most evidence, however, suggests that fitness penalties associated with fungicide resistance in other pathogens are either low (Billard et al. 2012; Kim and Xiao 2011) or completely absent (Corio-Costet et al. 2010). Further monitoring of mutation prevalence in A. solani populations conferring fungicide resistance will be important as foliar fungicide application regimes change or as new SDHI chemistries such as solatenol and adepidyn (Syngenta) are registered for use in potato.

\section{Acknowledgments}

We thank Bayer CropScience for financial support of this research.

\section{Literature Cited}

Avenot, H. F., and Michailides, T. J. 2010. Progress in understanding molecular mechanisms and evolution of resistance to succinate dehydrogenase inhibiting (SDHI) fungicides in phytopathogenic fungi. Crop Prot. 29:643-651.

Avenot, H. F., Sellam, A., Karaoglanidis, G., and Michailides, T. J. 2008. Characterization of mutations in the iron sulfur subunit of succinate dehydrogenase correlating with boscalid resistance in Alternaria alternata from California pistachio. Phytopathology 98:736-742.

Avenot, H. F., Sellam, A., and Michailides, T. J. 2009. Characterization of mutations in the membrane-anchored subunits AaSDHC and AaSDHD of succinate dehydrogenase from Alternaria alternata isolates conferring field resistance to the fungicide boscalid. Plant Pathol. 58:1134-1143.

Avenot, H. F., Thomas, A., Gitaitis, R. D., Langston, D. B., Jr., and Stevenson, K. 2012. Molecular characterization of boscalid- and penthiopyrad-resistant isolates of Didymella bryoniae and assessment of their sensitivity to fluopyram. Pest Manage. Sci. 68:645-651.

Bardas, G. A., Veloukas, T., Koutita, O., and Karaoglanidis, G. S. 2010. Multiple resistance of Botrytis cinerea from kiwifruit to SDHIs, QoIs and fungicides of other chemical groups. Pest Manage. Sci. 66:967-973.

Billard, A., Fillinger, S., Leroux, P., Lachaise, H., Beffa, R., and Debieu, D. 2012 Strong resistance to the fungicide fenhexamid entails a fitness cost in Botrytis cinerea, as shown by comparisons of isogenic strains. Pest Manage. Sci. 68:684-691.

Bolton, M. D., Rivera, V., and Secor, G. 2013. Identification of the G143A mutation associated with QoI resistance in Cercospora beticola field isolates from Michigan, United States. Pest Manage. Sci. 69:35-39.

Corio-Costet, M.-F., Dufour, M.-C., Cigna, J., Abadie, P., and Chen, W.-J. 2010 Diversity and fitness of Plasmopara viticola isolates resistant to QoI fungicides. Eur. J. Plant Pathol. 129:315-329.

Delgado, J. A., Lynnes, T. C., Meinhardt, S. W., Wise, K. A., Gudmestad, N. C., Bradley, C. A., Markell, S. G., and Goswami, R. S. 2013. Identification of the mutation responsible for resistance to Qol fungicides and its detection in Ascochyta rabiei (teleomorph Didymella rabiei). Plant Pathol. 62:688-697.

Dowling, M. E., Bryson, P. K., Boatwright, H. G., Wilson, J. R., Fan, Z., Everhart, S. E., Brannen, P. M., and Schnabel, G. 2016. Effect of fungicide applications on Monilinia fructicola population diversity and transposon movement. Phytopathology 106:1504-1512.

Fairchild, K. L., Miles, T. D., and Wharton, P. S. 2013. Assessing fungicide resistance in populations of Alternaria in Idaho potato fields. Crop Prot. 49:31-39.

Fonseka, D. L., and Gudmestad, N. C. 2016. Spatial and temporal sensitivity of Alternaria species associated with potato foliar diseases to demethylation inhibiting and anilino-pyrimidine fungicides. Plant Dis. 100:1848-1857. 
Franc, G. D., and Christ, B. J. 2001. Early blight. Pages 22-23 in: Compendium of Potato Diseases. W. R. Stevenson, R. Loria, G. D. Franc, and G. D. Weingartner, eds. American Phytopathological Society, St. Paul, MN.

Frederick, Z. A., Villani, S. M., Cooley, D. R., Biggs, A. R., Raes, J. J., and Cox, K. D. 2014. Prevalence and stability of qualitative QoI resistance in populations of Venturia inaequalis in the northeastern United States. Plant Dis. 98:1122-1130.

Gudmestad, N. C. S., Arabiat, S., Pasche, J. S., and Miller, J. S. 2013. Prevalence and impact of SDHI fungicide resistance in Alternaria solani. Plant Dis. 97:952-960.

Holm, A. L., Rivera, V. V., Secor, G. A., and Gudmestad, N. C. 2003. Temporal sensitivity of Alternaria solani to foliar fungicides. Am. J. Potato Res. 80:33-40.

Hu, M.-J., Cox, K. D., and Schnabel, G. 2016. Resistance to increasing chemical classes of fungicides by virtue of "selection by association" in Botrytis cinerea. Phytopathology 106:1513-1520.

Iacomi-Vasilescu, B., Bataille-Simoneau, N., Campion, C., Dongo, A., Laurent, E., Serandat, I., Hamon, B., and Simoneau, P. 2008. Effect of null mutations in the AbNIK1 gene on saprophytic and parasitic fitness of Alternaria brassicicola isolates highly resistant to dicarboximide fungicides. Plant Pathol. 57:937-947.

Ishii, H., Miyamoto, T., Ushio, S., and Kakishima, M. 2011. Lack of crossresistance to a novel succinate dehydrogenase inhibitor, fluopyram, in highly boscalid-resistant isolates of Corynespora cassiicola and Podosphaera xanthii. Pest Manage. Sci. 67:474-482.

Jiménez-Díaz, R. M., Olivares-García, C., Landa, B. B., Jiménez-Gasco, M. M., and Navas-Cortés, J. A. 2011. Region-wide analysis of genetic diversity in Verticillium dahliae populations infecting olive in southern Spain and agricultural factors influencing the distribution and prevalence of vegetative compatibility groups and pathotypes. Phytopathology 101:304-315.

Karaoglanidis, G., Thanassoulopoulos, C., and Ioannidis, P. 2001. Fitness of Cercospora beticola field isolates resistant and sensitive to demethylation inhibitor fungicides. Eur. J. Plant Pathol. 107:337-347.

Kim, Y. K., and Xiao, C. L. 2011. Stability and fitness of pyraclostrobinand boscalid-resistant phenotypes in field isolates of Botrytis cinerea from apple. Phytopathology 101:1385-1391.

Konstantinou, S., Veloukas, T., Leroch, M., Menexes, G., Hahn, M., and Karaoglanidis, G. 2015. Population structure, fungicide resistance profile, and $\mathrm{sdhB}$ mutation frequency of Botrytis cinerea from strawberry and greenhouse-grown tomato in Greece. Plant Dis. 99:240-248.

Landschoot, S., Carrette, J., Vandecasteele, M., De Baets, B., Höfte, M., Audenaert, K., and Haesaert, G. 2017. Boscalid-resistance in Alternaria alternata and Alternaria solani populations: An emerging problem in Europe. Crop Prot. 92:49-59.

Leiminger, J. H., Adolf, B., and Hausladen, H. 2014. Occurrence of the F129L mutation in Alternaria solani populations in Germany in response to QoI application, and its effect on sensitivity. Plant Pathol. 63:640-650.

Leroux, P., Gredt, M., Leroch, M., and Walker, A.-S. 2010. Exploring mechanisms of resistance to respiratory inhibitors in field strains of Botrytis cinerea, the causal agent of gray mold. Appl. Environ. Microbiol. 76:6615-6630.

Li, X., Fernández-Ortuño, D., Chen, S., Grabke, A., Luo, C.-X., Bridges, W. C., and Schnabel, G. 2014. Location-specific fungicide resistance profiles and evidence for stepwise accumulation of resistance in Botrytis cinerea. Plant Dis. 98:1066-1074.

Ma, Z., Felts, D., and Michailides, T. J. 2003. Resistance to azoxystrobin in Alternaria isolates from pistachio in California. Pestic. Biochem. Physiol. 77:66-74.

Mallik, I., Arabiat, S., Pasche, J. S., Bolton, M. D., Patel, J. S., and Gudmestad, N. C. 2014. Molecular characterization and detection of mutations associated with resistance to succinate dehydrogenase-inhibiting fungicides in Alternaria solani. Phytopathology 104:40-49.
Mikaberidze, A., McDonald, B. A., and Bonhoeffer, S. 2014. Can high-risk fungicides be used in mixtures without selecting for fungicide resistance? Phytopathology 104:324-331.

Miles, T. D., Miles, L. A., Fairchild, K. L., and Wharton, P. S. 2014. Screening and characterization of resistance to succinate dehydrogenase inhibitors in Alternaria solani. Plant Pathol. 63:155-164.

Pasche, J. S., and Gudmestad, N. C. 2008. Prevalence, competitive fitness and impact of the F129L mutation in Alternaria solani in the United States. Crop Prot. 27:427-435.

Pasche, J. S., Piche, L. M., and Gudmestad, N. C. 2005. Effect of F129L mutation in Alternaria solani on fungicides affecting mitochondrial respiration. Plant Dis. 89:269-278.

Pasche, J. S., Wharam, C. M., and Gudmestad, N. C. 2004. Shift in sensitivity of Alternaria solani to QoI fungicides. Plant Dis. 88:181-187.

Pscheidt, J. W., and Stevenson, W. R. 1988. The critical period for control of early blight (Alternaria solani) of potato. Am. Potato J. 65:425-438.

Scalliet, G., Bowler, J., Luksch, T., Kirchhofer-Allan, L., Steinhauer, D., Ward, K. Niklaus, M., Verras, A., Csukai, M., Daina, A., and Fonne-Pfister, R. 2012. Mutagenesis and functional studies with succinate dehydrogenase inhibitors in the wheat pathogen Mycosphaerella graminicola. PLoS ONE 7:e35429.

Sierotzki, H., and Scalliet, G. 2013. A review of current knowledge of resistance aspects for the next-generation succinate dehydrogenase inhibitor fungicides. Phytopathology 103:880-887.

Stammler, G., Brix, H. D., Glattli, A., Semar, M., and Schoefl, U. 2007. Biological properties of the carboxamide boscalid including recent studies on its mode of action. Pages 40-45 in: Proc. XVI Int. Plant Prot. Congr., Glasgow.

Stevenson, W. R., and James, R. V. 1999. Evaluation of fungicides to control early blight and late blight of potato-Hancock, 1998. Fungic. Nematicide Tests 54: 212-213.

Stewart, C., and Via, L. E. 1999. A rapid CTAB DNA isolation technique useful for RAPD fingerprinting and other PCR applications. Biotechniques 14: 748-749.

Thomas, A., Langston, D. B., Jr., and Stevenson, K. L. 2012. Baseline sensitivity and cross-resistance to succinate-dehydrogenase-inhibiting and demethylationinhibiting fungicides in Didymella bryoniae. Plant Dis. 96:979-984.

Van der Heyden, H., Dutilleul, P., Brodeur, L., and Carisse, O. 2014. Spatial distribution of single-nucleotide polymorphisms related to fungicide resistance and implications for sampling. Phytopathology 104:604-613.

Veloukas, T., Kalogeropoulou, P., Markoglou, A. N., and Karaoglanidis, G. S. 2014. Fitness and competitive ability of Botrytis cinerea field isolates with dual resistance to SDHI and QoI fungicides, associated with several $s d h \mathrm{~B}$ and the cytb G143A mutations. Phytopathology 104:347-356.

Veloukas, T., Leroch, M., Hahn, M., and Karaoglanidis, G. S. 2011. Detection and molecular characterization of boscalid-resistant Botrytis cinerea isolates from strawberry. Plant Dis. 95:1302-1307.

Veloukas, T., Markoglou, A. N., and Karaoglanidis, G. S. 2013. Differential effect of SdhB gene mutations on the sensitivity to SDHI fungicides in Botrytis cinerea. Plant Dis. 97:118-122.

Wharton, P., Fairchild, K., Belcher, A., and Wood, E. 2012. First report of in-vitro boscalid-resistant isolates of Alternaria solani causing early blight of potato in Idaho. Plant Dis. 96:454.

Yang, J. H., Brannen, P. M., and Schnabel, G. 2015. Resistance in Alternaria alternata to SDHI fungicides causes rare disease outbreak in peach orchards. Plant Dis. 99:65-70.

Yellareddygari, S. K. R., Pasche, J. S., Taylor, R. J., and Gudmestad, N. C. 2016 Individual participant data meta-analysis comparison of foliar fungicides applied for potato early blight management. Plant Dis. 100:200-206. 